\title{
A metric framework for evaluating the resilience contribution of hydropower to the grid
}

\section{October 2020}

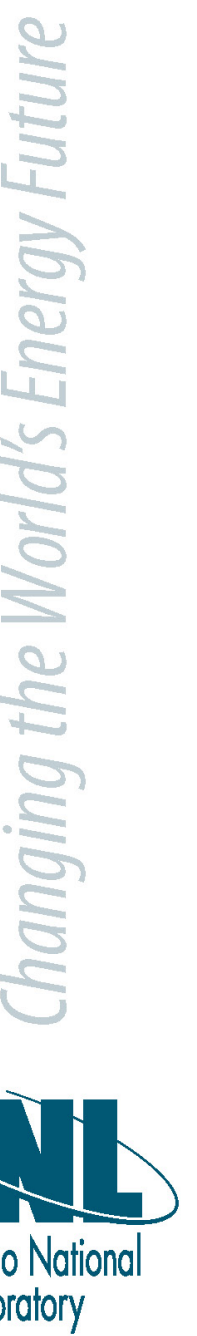

Tyler Bennett Phillips, Vishvas Chalishazar, Timothy R McJunkin, Manisha Maharjan, S M Shafiul Alam, Thomas M Mosier, Somani, Abhishek 


\section{DISCLAIMER}

This information was prepared as an account of work sponsored by an agency of the U.S. Government. Neither the U.S. Government nor any agency thereof, nor any of their employees, makes any warranty, expressed or implied, or assumes any legal liability or responsibility for the accuracy, completeness, or usefulness, of any information, apparatus, product, or process disclosed, or represents that its use would not infringe privately owned rights. References herein to any specific commercial product, process, or service by trade name, trade mark, manufacturer, or otherwise, does not necessarily constitute or imply its endorsement, recommendation, or favoring by the U.S. Government or any agency thereof. The views and opinions of authors expressed herein do not necessarily state or reflect those of the U.S. Government or any agency thereof. 


\section{A metric framework for evaluating the resilience contribution of hydropower to the grid}

Tyler Bennett Phillips, Vishvas Chalishazar, Timothy R McJunkin, Manisha Maharjan, S M Shafiul Alam, Thomas M Mosier, Somani, Abhishek

October 2020

Idaho National Laboratory

Idaho Falls, Idaho 83415

http://www.inl.gov

Prepared for the U.S. Department of Energy Under DOE Idaho Operations Office

Contract DE-AC07-05ID14517 


\title{
A Metric Framework for Evaluating the Resilience Contribution of Hydropower to the Grid
}

\author{
Tyler Phillips*, Vishvas Chalishazar ${ }^{\dagger}$, Timothy McJunkin ${ }^{\ddagger}$, Manisha Maharjan ${ }^{\ddagger}$, S M Shafiul Alam ${ }^{\ddagger}$, \\ Thomas Mosier ${ }^{\ddagger}$, Abhishek Somani ${ }^{\S}$ \\ *National \& Homeland Security, Idaho National Laboratory, Idaho Falls, ID 83415, USA \\ $\dagger$ Electricity Security, Pacific Northwest National Laboratory, Richland, WA 99354, USA \\ $\ddagger$ Power \& Energy Systems, Idaho National Laboratory, Idaho Falls, ID 83415, USA

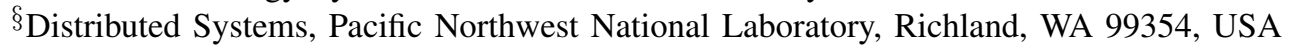

\begin{abstract}
This paper will describe a proposed framework for expressing the resilience of hydropower generation and provide initial case studies for three classes of hydropower, run-of-river hydropower, hydropower with reservoirs, and pumped storage hydropower. Hydropower has great flexibility to provide support during and after natural and man-made events that can disrupt critical infrastructure functionality. The concept of the framework provides for consideration of policy and rules, constraints of the water shed and other allocations of water, storage and plant capabilities to produce real and reactive power, and the strength of the delivery network. The paper details a resilience response metric that has inputs of state of storage and plant level constraints on real and reactive power production. Using the definition of resilience, based on maintaining a minimally normal operations, we provide a qualitative assessment of hydropower's ability to address the various time scales comprising the " $R$ "s of resilience.
\end{abstract}

Index Terms-resilience, hydropower.

\section{INTRODUCTION}

The electric power grid is undergoing a dramatic shifts in sources of power and increasing infrastructure stresses. The desire to improve the ability of the grid to ride through or recover from large events with natural or man-made causes have increased interest in the area of resilience for the electricity grid. The need arises to understand the resilience contribution from bulk power and distributed energy resources. Providing a quantifiable measure of resilience of all types of components in power systems to add resilience to the electric grid is needed. Creating a framework for characterizing the resilience of hydropower satisfies one of those needs and is the subject of this paper.

To arrive at a framework to measure resilience, relevant prior work is in engineering systems [1], national institutions [2], [3], and the resilient controls community [4]. This paper considers asset level and system level metrics in addition to metrics from [3]. Both asset and system metrics connect to

This manuscript has been authored in part by Battelle Energy Alliance, LLC under Contract No. DE-AC07-05ID14517 and Battelle under Contract No. DE-AC05-76RL01830 with the U.S. Department of Energy. Work supported through the U.S. Department of Energy Water Power Technology Office HydroWIRES Initiative.

Corresponding author: Timothy.McJunkin@inl.gov, ORCID: 0000-00024987-9170 the notional construction of the system performance compared to the performance objective in the Disturbance, Impact, Resilience, and Evaluation (DIRE) curve [5] shown in Fig. 1. Important time frames in the evolution of the effects of a disturbance on the system are mapped to the time frame of the DIRE curve as the "R"s of resilience: Reconnaissance, Resistance, Response, Recovery, and Restoration. Woods introduces the term adaptive capacity to assess a system's resilience based on the proximity of the operation point to a boundary constraint [6]. When operation is near a boundary, adaptive capacity to respond to disturbances is limited. A system operator that prudently anticipates disturbances will seek to keep adequate adaptive capacity. In power systems, stability can be characterized as the ability to maintain voltage and frequency within acceptable margins of the nominal value. Frequency stability requires the balancing of generation and load in terms of real power and voltage stability requires the balancing of reactive power. The resist epoch gives the system more time to respond. For power systems the determining resist factors are the voltage margin and the inertia in the system. In the response epoch, the magnitude and duration of a disturbance the system can absorb and maintain minimum operational normalcy is determined by the adaptive capacity of the system. In [7], McJunkin and Rieger constructed a method to efficiently capture and aggregate the response adaptive capacity of power system assets, which was extended to an asymmetric operational metric in [8].

The main contribution of this work is the formalization of an operational framework that allows evaluation of the contributions to resilience by three types of hydropower assets. From the framework, we show hydropower's contributions to the "R"s of resilience. The rest of the paper is organized as follows: Section II gives an overview of resilience and hydropower's contribution to the grid. Section III summarizes and adapts the mathematical background given in [8] for hydropower plants. Section IV introduces the proposed framework and applies the metric to different types of hydropower assets. Concluding remarks are given in Section $\mathrm{V}$ and future work is discussed in Section VI. 


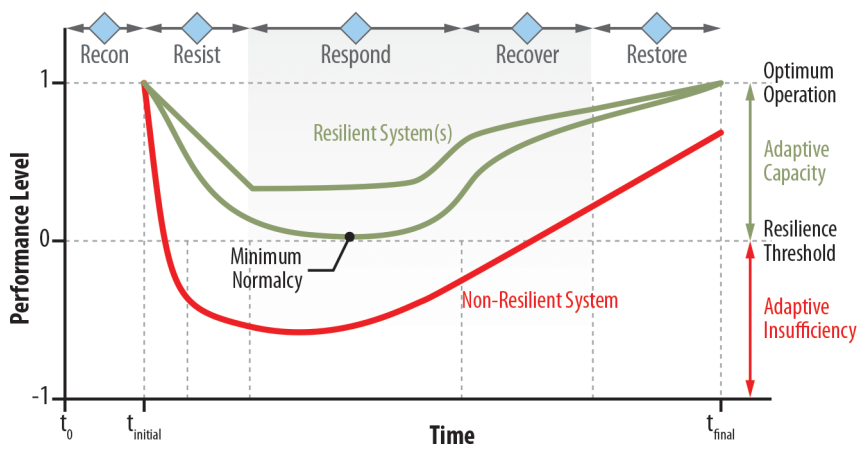

Fig. 1. A simplified version of the Disturbance and Impact Resilience Curve [4], [5].

\section{AdAPtive CAPACITy CONTRIBUtion OF HYDROPOWER}

\section{A. System Level}

The conceptual DIRE curve, Fig. 1, describes the performance level of the system as a whole, during and after a major disturbance or High Impact Low Probability (HILP) event. Most of the resilience studies use some form of the DIRE curve to develop and evaluate resilience metrics to know the system health and its ability to absorb, adapt and recover rapidly after an HILP event. Even though there are several resilience metrics already proposed it is still difficult to accurately quantify and represent resilience. Resilience is a complex multidimensional dynamic concept [9]. Numerous different metrics exist and some of the most relevant and commonly used metrics are:

- Demand/energy not served [10],

- The "FLEP" resilience metric system $(\Phi, \Lambda, \mathcal{E}, \Pi)$, where $\Phi$ is how fast and $\Lambda$ is how low the resilience level drops, $\mathcal{E}$ is for how extensive the post-event degraded state and $\Pi$ is how promptly the network recovers to its pre-event resilient state. [11], [12],

- Time to recovery, cost of recovery, load recovery factor and lost revenue [13], [14],

- Vulnerability index (VI), degradation index (DI), restoration efficiency index (REI) and microgrid resilience index (MRI) [15] , and

- Maximum number of customers out of service [16]

All of these metrics do a relatively good job at describing power systems resilience to an external disturbance, however, they are not very useful in describing the contribution of any particular power generation asset (for example the Grand Coulee hydropower plant) or family of generation assets (for example hydropower as a whole) towards achieving that level of resilience. To address this problem for the power transmission system, prior work has used augmentation of traditional bus-branch model into node-breaker model so that the fragility and vulnerability of each substation asset (such as the transformers and circuit breakers) can be included in the evaluation of resilience levels [17].

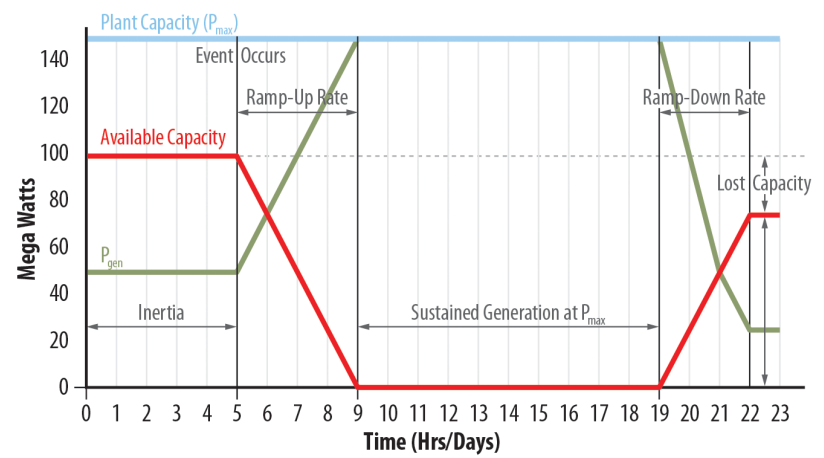

Fig. 2. Asset level metrics from a hydropower plant perspective.

Each family of assets contributes in its own way towards resilience and it is important to understand how to utilize these assets to their fullest potential. To that end, the asset level metrics for hydroelectric generation is discussed in the next sub-section to quantify its contribution towards resilience.

\section{B. Asset Level}

Hydropower generation has numerous qualities that contribute towards overall grid resilience. Hydro is also the preferred generation and is prioritized for tripping in case of over generation scenarios because of an extreme event. This is primarily because of the following reasons: 1) hydropower leads to least cost when compared to other generation trips, 2) pumped storage efficiency helps in restoring the hydro resource back by pumping spilled water and 3) it is easier to bring hydropower back online. Hydro is also the preferred generation for wind compensation [18] because it provides a major part of the total required governor response and also hydro can provide, if needed, more output than its nameplate capacity but at a lower efficiency. All of these qualities and capabilities make hydro's contribution to grid resilience significant and the proposed asset level metrics are a step in the direction to be able to accurately represent the said contribution.

A generic example of real power output generation of a hydropower plant going through a major grid scale disturbance event is shown in Fig. 2. Here, different asset level metrics are shown for different time periods before and after an event. These proposed metrics, their contributing capabilities and their constraints/dependencies are further discussed in Table I.

These metrics capture hydro asset's flexibility and its multifaceted contribution towards overall grid resilience and system stability which enables rapid recovery of the system following an extreme event. In this paper, we focus on the response epoch for hydropower resilience and describe the adaptive capacity fundamentals in the next section.

\section{HYDROPOWER RESPONSE CAPACITY}

The calculation of the adaptive capacity of hydropower plants is based on the real and reactive power generation capability, the current operating output, latency, ramp rate, and energy constraints. The first constraint on the operational 
TABLE I

ASSET LEVEL METRICS, THEIR CAPABILITIES AND THEIR DEPENDENCIES

\begin{tabular}{lll}
\hline Metrics & Epoch & Dependencies/constraints \\
\hline Inertia & Resist & $\begin{array}{l}\text { Number of online units, } \\
\text { Seasonal Constraints, } \\
\text { Planned maintenance, etc. }\end{array}$ \\
\hline Ramp-up rate & Respond & $\begin{array}{l}\text { Number of online units, } \\
\text { Environmental constraints, } \\
\text { Flow rate Constraints, etc. }\end{array}$ \\
\hline $\begin{array}{l}\text { Sustained generation } \\
\text { at maximum output }\end{array}$ & Recover \& & $\begin{array}{l}\text { Resource availability, } \\
\text { Environmental constraints, } \\
\text { Energy limits, etc. }\end{array}$ \\
\hline \multirow{2}{*}{ Ramp-down rate } & Respond & $\begin{array}{l}\text { Flow rate constraints, } \\
\text { Environmental constraints, } \\
\text { Grid requirements, etc. }\end{array}$ \\
\hline & & Initial capacity, \\
Lost capacity & Restore \& & $\begin{array}{l}\text { Impact of extreme event, } \\
\text { Amount of sustained } \\
\text { generation at } \\
\text { maximum output, etc. }\end{array}$ \\
\hline
\end{tabular}

power output of the asset in real power, $P$, and reactive power, $Q$, is defined by the complex S-plane. At any given power factor angle, $\theta$, the apparent power is bounded by

$$
S(\theta) \leq \sqrt{P^{2}+Q^{2}}, \quad 0 \leq \theta<2 \pi
$$

In the context of hydropower generators and pumped storage hydropower (PSH), the apparent power is not the only constraint on the power output. The real power is also constrained, given mathematically as

$$
P(\theta)= \begin{cases}\min \left[S \cos (\theta), P_{\max }\right], & 0 \leq \theta<\frac{\pi}{2} \\ \min \left[S \cos (\theta), P_{\max }\right], & \frac{3 \pi}{2}<\theta<2 \pi \\ -\min \left[|S \cos (\theta)|,\left|P_{\min }\right|\right], & \frac{\pi}{2} \leq \theta \leq \frac{3 \pi}{2}\end{cases}
$$

here, the generator only operates in the positive plane so $P_{\min }=0$. Additionally, the maximum real power, $P_{\max }$, may not be the nameplate capacity due to a decrease in the reservoir head height. On the other hand, PSH can also operate in the negative plane (pump mode) and positive plane (generation mode).

The flexibility of the asset is defined as the amount of change it can make from the current operating point to the bounding limits. Thus, it is the translation from $P=0, Q=0$, to the operating point, $P_{0}$ and $Q_{0}$. The limits on the operating power $S, P_{\max }$ and $P_{\min }$ then take the form $S^{\prime}, P_{\max }^{\prime}$, and $P_{\min }^{\prime}$ after the translation, given mathematically as

$$
P_{\Delta}(\theta)= \begin{cases}\min \left[S^{\prime} \cos (\theta), P_{\max }^{\prime}\right], & 0 \leq \theta \leq \frac{\pi}{2} \\ \min \left[S^{\prime} \cos (\theta), P_{\max }^{\prime}\right], & \frac{3 \pi}{2} \leq \theta<2 \pi \\ -\min \left[\left|S^{\prime} \cos (\theta)\right|,\left|P_{\min }^{\prime}\right|\right], & \frac{\pi}{2}<\theta<\frac{3 \pi}{2}\end{cases}
$$

for the real power. The reactive power is given as

$$
Q_{\Delta}=S^{\prime} \sin (\theta)
$$

The flexibility of a hydropower generator is shown in Fig. 3. This example depicts a $10 \mathrm{MW}$ generator that is currently being operated at $6 \mathrm{MW}$ and 2 MVAR. The shaded region in the top plot represent the flexibility when the asset is limited by $P_{\max }^{\prime}$ due to a reduced reservoir head height. The apparent power limits shown here are a simplification of the general constraints of a generator like the capability curve shown in [19], [20]. A more accurate constraint can be added to the metric in the future. The flexibility does not consider the temporal constraints of the asset which define how quick it can change from its current operating output to the flexibility limits.

Temporal constraints of the asset are captured by the latency and ramp rate. Latency is the time lag before the asset can begin changing its output. It may consist of multiple factors, such as grid synchronization and decisions which can be done computationally or by an operator. In this work, we consider all latency to be contained in a single variable, $\lambda$.

The ramp rate defines the rate of change in real or reactive power after the latency. Again, hydropower assets have several considerations such as automatic generation control (AGC) and environmental regulations. In this work, we consider these to be contained in a single variable for the ramp rate in real power, $d P / d t$, and reactive power, $d Q / d t$. Thus, the temporal real power constraint, relative to the current real power output, is given as

$$
P(t)= \begin{cases}0 & \text { if } t \leq \lambda \\ \frac{d P}{d t}(t-\lambda) & \text { if } t>\lambda\end{cases}
$$

and the reactive power is

$$
Q(t)= \begin{cases}0 & \text { if } t \leq \lambda \\ \frac{d Q}{d t}(t-\lambda) & \text { if } t>\lambda\end{cases}
$$

where $t$ is the future time from current operation. In addition, the ramp rates may be direction dependent and non-linear, i.e. the asset may ramp down quicker than it can ramp up. We denote the the real power constraint as $P(t)^{+}$when ramping up and as $P(t)^{-}$when ramping down. The same is done for the reactive power. The temporal constraints in real power are shown in the bottom plot in Fig. 3.

The adaptive capacity is then calculated as the minimum between the temporal constraint and the flexibility of the asset. The adaptive capacity in real power is given as

$$
P_{\mathrm{AC}}(\theta, t)= \begin{cases}\min \left[P_{\Delta}, P(t)^{+}\right], & 0 \leq \theta<\frac{\pi}{2} \\ \min \left[P_{\Delta}, P(t)^{+}\right], & \frac{3 \pi}{2}<\theta<2 \pi \\ -\min \left[\left|P_{\Delta}\right|,\left|P(t)^{-}\right|\right], & \frac{\pi}{2} \leq \theta \leq \frac{3 \pi}{2}\end{cases}
$$

and the adaptive capacity in reactive power is given as

$$
Q_{\mathrm{AC}}(\theta, t)= \begin{cases}\min \left[Q_{\Delta}, Q(t)^{+}\right], & 0 \leq \theta \leq \pi \\ -\min \left[\left|Q_{\Delta}\right|,\left|Q(t)^{-}\right|\right], & \pi<\theta<2 \pi\end{cases}
$$

The adaptive capacity in real power where $\theta=0$ and $\pi$ over 12 minutes is depicted in the bottom plot of Fig. 3. It can be seen that the adaptive capacity is initially limited by the temporal constraints, but after ramping, the flexibility constraints are reached and constrain the adaptive capacity of the asset. 

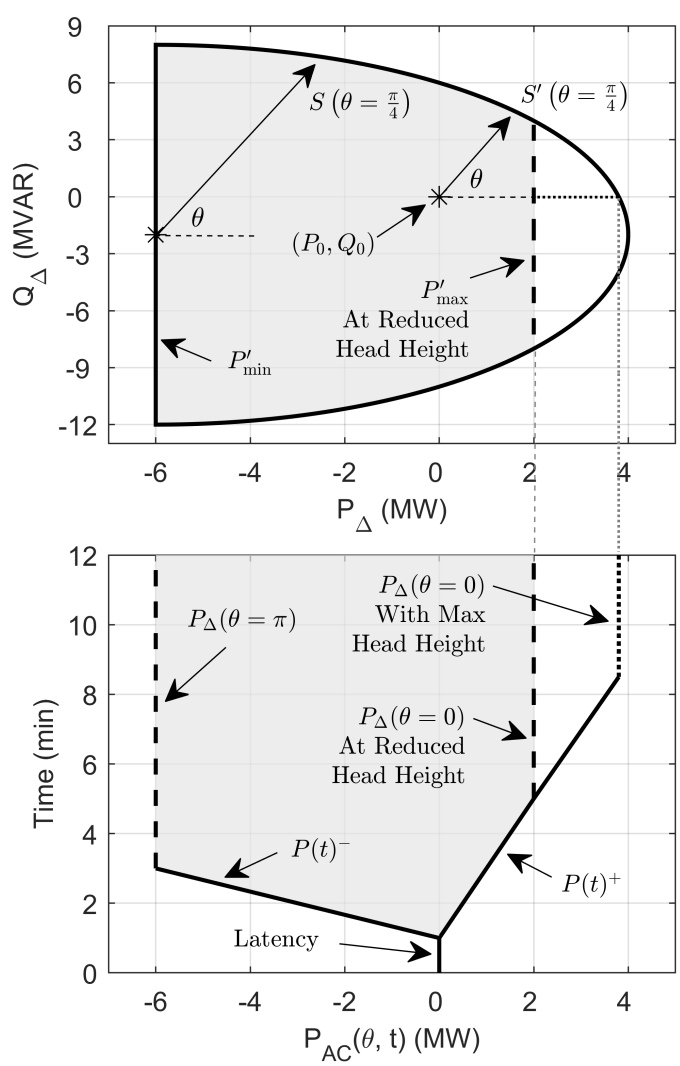

Fig. 3. The top plot depicts the flexibility of a $10 \mathrm{MW}$ hydropower generator operated at $6 \mathrm{MW}$ and 2 MVAR using the transformation from $S$ to $S^{\prime}$. The highlighted region represents the flexibility when there is a reduced reservoir head height limiting the real power at $P_{\max }^{\prime}$. The bottom plot illustrates the temporal and flexibility constraints on the adaptive capacity calculation in real power at $\theta=0$ and $\pi$ over 12 minutes.

Furthermore, the adaptive capacity of assets can be aggregated in real and reactive power where the angle measurement is consistent from the operation point. The aggregation of real power is given as

$$
P_{\mathrm{AC}}(\theta, t)=\sum_{k=1}^{n} P_{\mathrm{AC}_{k}}
$$

and the reactive power is given as

$$
Q_{\mathrm{AC}}(\theta, t)=\sum_{k=1}^{n} Q_{\mathrm{AC}_{k}}
$$

where $n$ represents the total number of aggregated assets. $P_{\mathrm{AC}_{k}}$ and $Q_{\mathrm{AC}_{k}}$ represent the adaptive real and reactive power capacity of the $k^{\text {th }}$ asset, respectively. For a detailed mathematical background, the reader is referred to [8]. In the following section, we carry out a series of case studies to demonstrate the difference in adaptive capacity between three types of hydropower assets: 1) run-of-river hydropower (ROR), 2) hydropower with reservoir (HWR), and 3) PSH.

\section{FRAMEWORK}

This section provides a description of the framework for incorporating the factors that influence hydropower's avail-

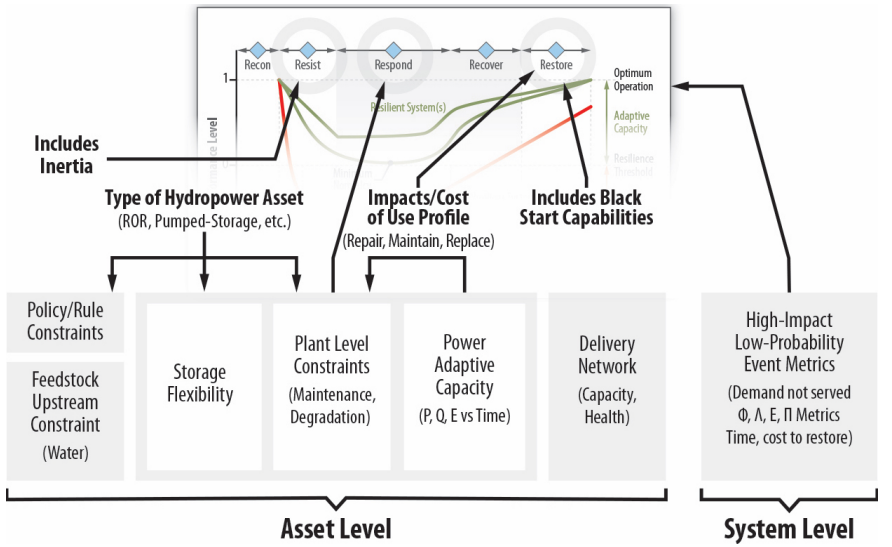

Fig. 4. Hydropower framework connecting the constraints on the capability to aid the resilience of the power systems.

able response for different types of hydropower resources in terms of operational flexibility and technical constraints. We illustrate the adaptive capacity resilience metric. The study includes a case for each of the three different types of hydropower assets. Input parameters were selected to convey the adaptive capacity concept and display their ability to support stability of the power grid.

Fig. 4 presents a hydropower framework that identifies contributions of hydropower asset in different epochs of the DIRE curve. There are numerous factors to consider while assessing hydropower asset's contribution to grid resilience. These factors like storage flexibility, plant level constraints, adaptive capacity and regulatory policies differ with the type of hydropower resource and alters the hydro's resilience response. In this paper, we focus on the adaptive capacity as it plays a key role in managing infrastructure integrity and service reliability [21].

Major operational constraints like maximum and minimum amount of power that can be generated, operation and maintenance requirements, ramping rates conditions, and elevation levels [22] are considered in all three types of hydropower. Water quantity, water head height, and reservoir level are the raw data that determines the amount of power generated by the hydropower asset. The plant level constraints, such as the operational capabilities of the generators, optimal operating range of the turbines, and the turbine efficiency also affects the reaction of the hydropower. Likewise, regulatory and environmental constraints, such as minimum water discharge, reservoir level restrictions, flow rate requirements, downstream impacts and power purchase contracts and agreements, also limit the functional capabilities of these hydropower plants [23]. The framework indicates that the strength and health of electricity delivery network is a key factor in the effectiveness of any asset's resilience contribution. The effectiveness of real and reactive power capabilities is tied to the plants' location and the type of transmission or distribution network connected to the plant. Some of the unique attributes of these hydropower are discussed below. 


\section{A. Run-of-River Hydropower}

ROR utilizes the natural flow of water from a river through a canal or penstock and the elevation gradient between the diversion and the powerhouse, usually with no or little reservoir [24]. ROR, generally, provides baseload with some variability in operation (typically for hourly or daily water availability fluctuations), but is unable to provide ancillary services to the grid due to inflexibility in generation. Runoff patterns can vary significantly seasonally and are driven by local or upstream hydrologic conditions. Because a plant may not be designed to utlilize less than the seasonal maximum flows for power production, during high inflow seasons, ROR plants may spill significant portion of the water without generating electricity [25]. ROR hydropower plants are typically designed to optimize financial performance with increasing capacity leading to a more expensive plant but a smaller capacity leading to lower revenues [26]. Although less variable, ROR is similar to solar or wind power, in that it is most often used as a maximum energy production. To achieve flexibility, a trade off between flexibility in power production versus maximum energy conversion must be made.

ROR projects cause less environmental concerns as no major construction of reservoir to raise the head height is needed and minimal amount of storage is involved [27]. However, restrictions on minimum amount and temperature of water discharge, and ramping rates apply for conservation of aquatic species and their habitat [28].

1) Case Study: We consider a ROR hydropower asset with a nameplate capacity at the current river flow of $10 \mathrm{MW}$ real power and \pm 10 MVAR reactive power. No presence of upstream or downstream dams or reservoirs is assumed for this asset. The current operating output of the turbine generator is $6 \mathrm{MW}$ of real power and 2 MVAR reactive power. As the head height of an ROR asset remains constant, the maximum real power which the asset can produce is dependent only on river flow rate over time. For this reason, the flexibility of power remains constant. It can be ramped up $4 \mathrm{MW}$ to its nameplate capacity of $10 \mathrm{MW}$ or it can be ramped down to $0 \mathrm{MW}$. At first glance, it would be easy to assume that the asset can also provide \pm 10 MVAR of reactive power. However, if the real power remains constant at $6 \mathrm{MW}$ the reactive power is limited to \pm 8 MVAR due to the apparent power constraint. Next, we consider the temporal constraints of the adaptive capacity.

When the generator is providing power, it is synchronized with the grid and the latency to make output adjustments comes from the AGC. Therefore, the latency in this study is set at $1 \mathrm{~s}$, which is a conservative assumption for resolving a frequency measurement that is an input to AGC. The ramp up and down rate for real power is assumed to be linear at $1 \mathrm{MW} / \mathrm{min}$ and the rate for reactive power is assumed to be $1.5 \mathrm{MVAR} / \mathrm{min}$. The resulting adaptive capacity from the current operating point is shown by the left plot in Fig. 5. The surface represents the maximum change in real and reactive power the asset can have over time. Next, we consider a hydropower asset with reservoir.

\section{B. Hydropower with Reservoir}

This type is characterized by the use of dam to store water in a reservoir, which facilitates the alteration of the water flow according to the system demand. It provides base load as well as the ability to shut down and start up quickly during peak load. It also provides the storage capacity to operate independently, without continually adjusting power generated to the flow of the river. The design, type and size of reservoir depends on landscape and nature of the plant site and economics of reservoir construction [26]. HWR have the ability to impound the inflows and then release when necessary for low-cost integration of variable renewables into the grid. However, this flexibility also contributes to increased financial risks, and operations and maintenance costs [29] and potential reduction of generation and reliability of plant components.

These reservoirs are often tied to regulations to serve environmental, recreation and irrigation purposes. Therefore, the release of water from the reservoir is limited to maintain consistent reservoir level for recreation, to prevent flooding, and support the habitat of the aquatic life. The thermal stratification of water and gas dissolution during water spillage also adds to the limitations of reservoir water release. The sediment, accumulated over time, within the reservoir also reduces the available storage capacity, which affects the amount of energy produced by the hydropower asset.

1) Case Study: In general, HWR has a larger nameplate power capacity than a ROR asset due to increased head height. However, to compare different hydropower assets we consider the same $10 \mathrm{MW}, \pm 10 \mathrm{MVAR}$ generator with the same latency and ramping rates. Therefore, the difference between the ROR and HWR is the potential for fluctuating reservoir depth, i.e. changing head height. As a result, the real power generation capability of the asset may not stay constant at the nameplate capacity of $10 \mathrm{MW}$.

To demonstrate how the head height effects the adaptive capacity we use a forecasted head height and apply a linear reduction to the maximum real power. Again, we assume the current operating point of the generator is $6 \mathrm{MW}$ and 2 MVAR. The corresponding adaptive capacity is shown by the center plot in Fig. 5. It can be seen that the adaptive capacity in real power is reduced when the head height is decreasing. It should be noted that the reduction in head height here is for demonstration purposes and unlikely that a reservoir would change depth this rapidly. In addition, the head height would be expected to remain constant if the power generating flow and spill were equal to the reservoir inflow and evaporation. When these are not equal changing volume tied to a function of volume versus head height would drive the change in the maximum real power available.

\section{Pumped Storage Hydropower}

Pumped storage hydropower (PSH) pumps water to upper reservoir during low power demand using surplus energy from the system, later releasing it to support peak demand. PSH compliments the intermittent power resources like solar and wind, as it replicates the behavior of a battery to store excess 

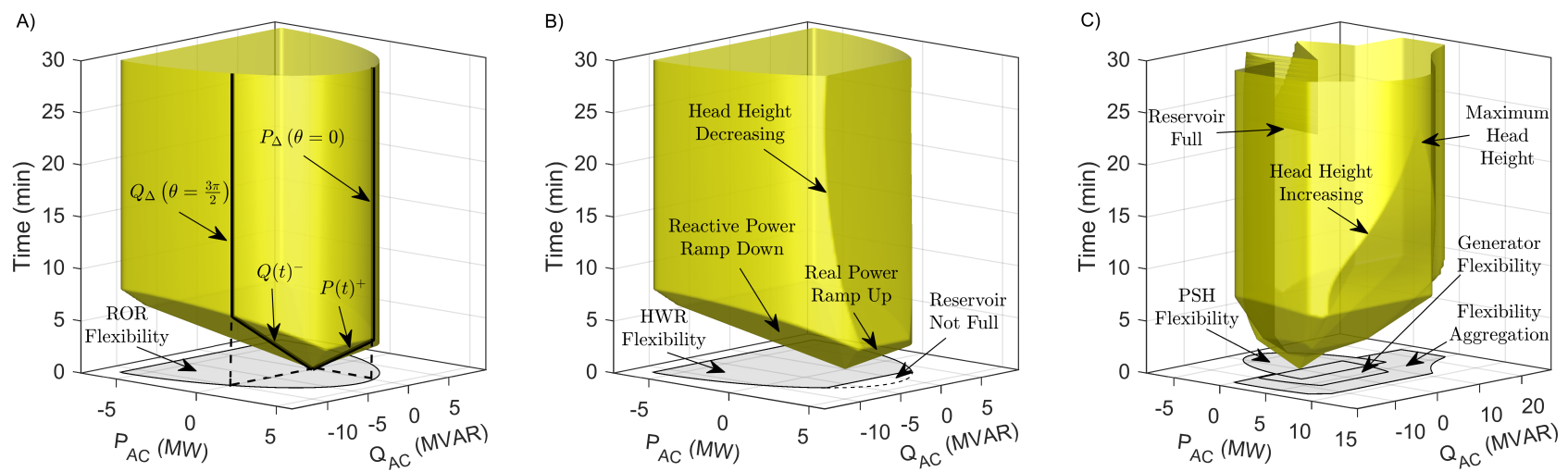

Fig. 5. Adaptive capacity in real power, $P_{\mathrm{AC}}$, and reactive power, $Q_{\mathrm{AC}}$, of different hydropower assets. A) $10 \mathrm{MW}$ ROR hydropower asset that is currently operating at $6 \mathrm{MW}$ of real power and 2 MVAR reactive power. B) $10 \mathrm{MW}$ reservoir based hydropower asset that is currently operating at $6 \mathrm{MW}$ and $2 \mathrm{MVAR}$ where head height is decreasing over time. C) Aggregated adaptive capacity of a 10 MW PSH when running in the pumping state at 3 MW and -4 MVAR.

electricity generated and also backs up the sources during low/no production. The amount of electric energy stored depends on the water storage capacity and differential height between the reservoirs [30]. Due to these characteristics, PSH has been an important asset on utility-scale storage, grid reliability, resiliency and many other ancillary services like regulation, operating reserves, etc. Furthermore, adjustable speed PSH can deliver fast ramping and frequency regulation in both the generation and pump modes. This technology also allows turbine to operate in peak efficiency under all head conditions, resulting increased energy generation [31]. Similarly, advanced PSH technology called ternary units, offer additional operational flexibility, increased efficiency and faster transition time between generating and pumping modes [32]. It also operates in hydraulic short circuit (HSC) mode which aids adjustable pump load [33]. Consequently, PSH with advanced design can provide a faster switching from pump to generation utilizing the HSC mode [34].

Conventionally, PSH were integrated on-stream (also known as open loop), assisting the ROR for water storage and rarely used in pumped storage mode to meet peak demand. Open loop PSH is subjected to all the reservoir related constraints. The PSH independent of natural water body, referred as closed loop, has the advantage of no to minimal impact on existing river systems [31]. The water inflow pattern in closed loop PSH is only affected by evaporation or seepage losses. PSH is confined to reservoir-based constraints similar to HWR, but is more flexible and efficient than the latter.

1) Case Study: We consider the scenario of excess generation and place a closed loop ternary $10 \mathrm{MW}$ PSH in the pumping state at $3 \mathrm{MW}$ and -4 MVAR. We use the same 10 MW machine as previous case studies and assume the pump has the same latency and ramp rate characteristics as the generator. The adaptive capacity of the ternary PSH is calculated as an aggregation of the adaptive capacity of the pump and generator. However, the pump and generator assets must consider their coupled relationship and transition states. Therefore, the calculated adaptive capacity of the pump and
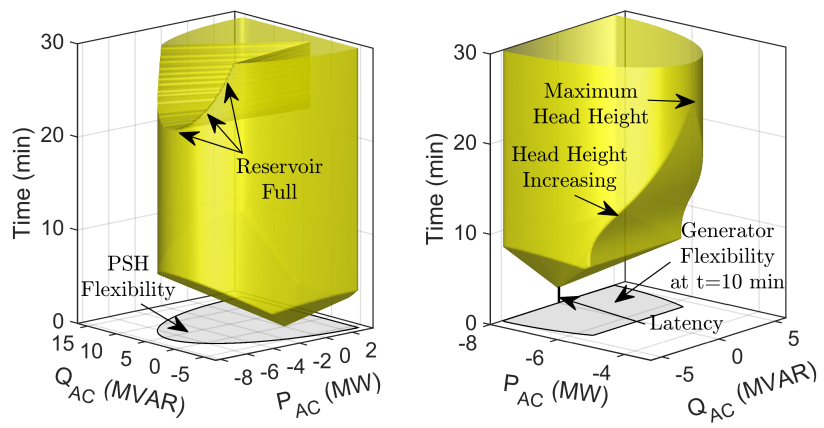

Fig. 6. The left plot shows the adaptive capacity of the $10 \mathrm{MW}$ pump operating at $3 \mathrm{MW}$ and -4 MVAR. The right plot shows the adaptive capacity of the $10 \mathrm{MW}$ generator at idle with a 90 second latency.

generator are from their current operating point and state of the system. With this consideration, the latency for the pump is 1 second and the latency for the generator is 90 seconds because of the transition state from pumping to generation [34].

Results of the adaptive capacity of the pump and generator are shown in Fig. 6, and the aggregation of the assets is shown by the right plot in Fig. 5. It can be seen that under current operation and forecasting, the maximum potential of the generator is increasing as the reservoir fills. As a result, the ternary PSH will need to change states to HSC where both the pump and generator are running, or water will need to be passed over the spillway.

\section{Discussion}

The following are general observations and comparisons of the three types of hydropower discussed in this paper. The ROR asset operates with constant head with little to no flexibility in generation and have limited ramping capability. This is reflected through fixed maximum real power capacity in Fig. 5(A). Furthermore, bidirectional variation in reactive power capacity exists but is constrained through the ROR asset's apparent power. In general, the reservoir based hydropower offers higher generation and ramping capability with 
reduced dependence on flow rate of water. However, as shown in Fig. 5(B), head uncertainty affects the adaptive capacity with higher variability as compared to ROR hydropower.

PSH with advanced design, for example, the ternary PSH can avoid spillage of excess water in pump mode while reaching the maximum head by operating in HSC mode shown in Fig. 5(C). Such spillage is unavoidable for ROR and reservoir based hydropower to maintain water flow rate (ROR) and reservoir capacity (reservoir based).

Overall, PSH offers the highest adaptive capacity through the variable storage and pump-generation switching capability. ROR hydropower offers the least due to the absence of a reservoir while a reservoir based hydropower performs better than ROR. It should be noted that, the current study considers only the effects of generation capacity, ramp rate and storage, while the ageing effects as well as environmental and regulatory constraints will be explored in future works.

Although this paper is focused on the response epoch of resilience, hydropower has other attributes that support the other Rs. Table II provides a qualitative summary of the resilience capabilities of the three types of hydropower assets. Recon epoch will determine the bias of the hydropower plants and determine the amount of flexibility the system has. The state of storage and power set points provide the starting point for the response to any disturbance. For example, the current state of the PSH systems, i.e., pumping or generating, will have a definitive affect on the response latency and ramping ability. Resist capabilities reside in the amount of inertia the plants have in their prime movers. Synchronous generators of ROR, HWR, and in instances where PSH is comprised of synchronous machines have these capabilities. Adjustable speed PSH utilizing converter-fed synchronous machines do not have this attribute. All types of hydropower have response capabilities, through governor, AGC, and other real and reactive control. The recover epoch is supported through longer term allocation of the response phase resources but also include dispatch decisions. While not covered in this paper, the authors anticipate that connecting the response capabilities of resources to production cost modeling would support dispatch decision. This would ensure optimal use of the resources to return the system towards the normal operating state. Finally, restore attributes of all hydropower include the use of the plants as the starting point of the black start cranking paths, because they require low initial power to start up, have fast ramping characteristics and large capacities [35], [36], as well as sustained generation for longer time frame after a major event. Restoration must consider the impacts to the hydropower assets during these events that may cause greater maintenance and repair needs of the plants.

\section{CONCLUSION}

This article has provided a framework for considering the resilience contribution of three classes of hydropower generation plants. The foundations of resilience definitions and measures are considered. The contribution of hydropower systems to resilience is considered in two tiers, system and asset level
TABLE II

SUMMARY OF RESILIENCE CAPABILITIES OF THE THREE TYPES OF HYDROPOWER ASSETS BY EPOCHS OF RESILIENCE.

\begin{tabular}{|c|c|c|c|}
\hline Epoch & ROR & HWR & $\mathrm{PSH}$ \\
\hline Recon & $\begin{array}{l}\text { power/ } \\
\text { spill } \\
\text { bias }\end{array}$ & $\begin{array}{l}\text { storage } \\
\text { power } \\
\text { bias }\end{array}$ & $\begin{array}{l}\text { storage } \\
\text { power } \\
\text { bias }\end{array}$ \\
\hline Resist & inertia $(\mathrm{H})$ & inertia $(\mathrm{H})$ & $\begin{array}{l}\text { depends } \\
\text { on type }\end{array}$ \\
\hline Respond & $\begin{array}{l}\text { real/ } \\
\text { reactive } \\
\text { spinning } \\
\text { reserve }\end{array}$ & $\begin{array}{l}\text { real } \\
\text { reactive } \\
\text { spinning/ } \\
\text { non-spinning } \\
\text { reserve }\end{array}$ & $\begin{array}{l}\text { real } \\
\text { reactive } \\
\text { ramp } \\
\text { dependent } \\
\text { on direction }\end{array}$ \\
\hline Recover & N/A & $\begin{array}{l}\text { dispatch/ } \\
\text { response }\end{array}$ & $\begin{array}{l}\text { dispatch/ } \\
\text { response }\end{array}$ \\
\hline Restore & $\begin{array}{l}\text { black } \\
\text { start \& } \\
\text { sustained } \\
\text { generation }\end{array}$ & $\begin{array}{l}\text { black } \\
\text { start \& } \\
\text { sustained } \\
\text { generation }\end{array}$ & $\begin{array}{l}\text { black } \\
\text { start \& } \\
\text { sustained } \\
\text { generation }\end{array}$ \\
\hline
\end{tabular}

resilience. System level resilience means the rate at which the operations of the electric grid are brought back to normal after an HILP. The contribution of a class of assets to the return to normal process should be valued in comparison to all supporting assets in the grid. Although the framework for asset level resilience seeks to encompass all the epochs of resilience, the initial focus is on the response epoch adaptive capacity for each type of hydropower asset. The comparison discussed is more about making utilities and stakeholders aware of the resilient capabilities held by these plants than to say one is preferable to another. The value is always in the context of the location of the plants and their role juxtaposed to the capabilities of all of the power system assets.

This work provides a framework for hydropower that could be adapted to the constraints of other energy assets on the grid. The specific capability captured through the adaptive capacity of hydropower assets was needed to allow resiliency analysis of portions of the electric grid and the grid as a whole. The paper focused on the response capacity of the three types of hydropower systems. With this framework and metrics tool, the ability for hydropower-specific assets can be compared or combined with other contributors to resilience: bus level adaptive capacity in transmission [37], distributed energy resources [7] including solar [8] to assess the magnitude and duration of disturbances the system could withstand without further anticipated failures. One of the most striking attributes of hydropower in general is the ability to support all of the time frames considered in the DIRE curve. Of course, there are trade-offs between the use in the response epoch, reserving capabilities for recover and restore, and maximum energy production; however, with an understanding of the capabilities and trade-offs, stakeholders can make informed decisions on prioritization of resource usage. 


\section{FUTURE WORK}

Several aspects of the framework require additional attention. Firstly, the adaptive capacity needs to incorporate synchronous generators' capability curves [19]. Secondly, there is a need to connect asset level metrics to the predicted outcomes contained in the system level metrics given the scale of HILP. Thirdly, the mechanics to connect the asset contribution to the needed location and the contribution of inertia need development. Finally, the inputs to the framework require coordination with analysis tools that provide more detailed treatment of the limits from environmental, storage and operational constraints.

\section{REFERENCES}

[1] E. Hollnagel, D. Woods, and N. Leveson, Resilience Engineering: Concepts and precepts. Ashgate Publishing, 2006.

[2] National Acedemies of Sciences, Engineering, and Medicine, "Enhancing the resilience of the nation's electricity system," https://doi.org/10.17226/24836, 2017.

[3] F. Petit and V. Vargas. (2020) Grid modernization: Metrics analysis (gmlc1.1) - resilience. [Online]. Available: https://gmlc.doe.gov/sites/default/files/ resources/GMLC1.1_Vol3_Resilience.pdf

[4] C. G. Rieger, D. I. Gertman, and M. A. McQueen, "Resilient control systems: Next generation design research," in 2009 2nd Conference on Human System Interactions, May 2009, pp. 632-636.

[5] C. G. Rieger, "Resilient control systems practical metrics basis for defining mission impact," in 2014 7th International Symposium on Resilient Control Systems (ISRCS), Aug 2014, pp. 1-10.

[6] D. Woods, Resilience Engineering: Concepts and Precepts. CRC Press, 2017.

[7] T. R. McJunkin and C. G. Rieger, "Electricity distribution system resilient control system metrics," in 2017 Resilience Week (RWS), Sep. 2017, pp. 103-112.

[8] T. Phillips, T. McJunkin, C. Rieger, J. Gardner, and H. Mehrpouyan, "An operational resilience metric for modern power distribution systems," in 2020 IEEE International Conference on Software Quality, Reliability and Security Companion (QRS-C), Requirements, 2020.

[9] M. Panteli and P. Mancarella, "The grid: Stronger, bigger, smarter?: Presenting a conceptual framework of power system resilience," IEEE Power and Energy Magazine, vol. 13, no. 3, pp. 58-66, 2015.

[10] B. Johnson, V. Chalishazar, E. Cotilla-Sanchez, and T. K. Brekken, "A monte carlo methodology for earthquake impact analysis on the electrical grid," Electric Power Systems Research, vol. 184, p. 106332, 2020.

[11] M. Panteli, P. Mancarella, D. Trakas, E. Kyriakides, and N. Hatziargyriou, "Metrics and quantification of operational and infrastructure resilience in power systems," IEEE Transactions on Power Systems, vol. 32, no. 6, pp. 4732-4742, Nov 2017.

[12] M. Panteli, D. N. Trakas, P. Mancarella, and N. Hatziargyriou, "Power systems resilience assessment: Hardening and smart operational enhancement strategies," Proceedings of the IEEE, vol. 105, no. 5, pp. 1202-1213, 2017.

[13] V. Chalishazar, "Evaluating the seismic risk and resilience of an electrical power system," PhD Dissertation, Oregon State University, 2019.

[14] V. Chalishazar, T. Brekken, D. Johnson, K. Yu, J. Newell, K. Chin, R. Weik, E. Dierickx, M. Craven, M. Sauter, A. Olennikov, J. Galaway, and A. Radil, "Connecting risk and resilience for a power system using the portland hills fault case study," Processes, vol. 8, no. 10: 1200, 2020.

[15] M. Amirioun, F. Aminifar, H. Lesani, and M. Shahidehpour, "Metrics and quantitative framework for assessing microgrid resilience against windstorms," International Journal of Electrical Power \& Energy Systems, vol. 104, pp. 716-723, 2019.

[16] M. Kazama and T. Noda, "Damage statistics (summary of the 2011 off the pacific coast of tohoku earthquake damage)," Soils and Foundation, 2012.

[17] V. Chalishazar, B. Johnson, E. Cotilla-Sanchez, and T. K. A. Brekken, "Augmenting the traditional bus-branch model for seismic resilience analysis," in 2018 IEEE Energy Conversion Congress and Exposition (ECCE), 2018, pp. 1133-1137.
[18] K. Choopani, R. Effatnejad, and M. Hedayati, "Coordination of energy storage and wind power plant considering energy and reserve market for a resilience smart grid," Journal of Energy Storage, vol. 30, p. 101542, 2020.

[19] D. Esmaeil Moghadam, A. Shiri, S. Sadr, and D. A. Khaburi, "A practical method for calculation of over-excited region in the synchronous generator capability curves," in 2014 IEEE 23rd International Symposium on Industrial Electronics (ISIE), 2014, pp. 727-732.

[20] O. Usta, M. MUSA, M. Bayrak, and M. Redfern, "A new relaying algorithm to detect loss of excitation of synchronous generators," Turk Journal of Electrical Engineering, vol. 15, 112007.

[21] M. Hellmuth, P. Cookson, and J. Potter, "Addressing climate vulnerability for power system resilience and energy security: A focus on hydropower resources," RALI Series: Promoting Solutions for Low Emission Development, May 2017, USAID Report.

[22] T. D. Veselka, S. Hamilton, and J. McCoy, "Optimizing hourly hydro operations at the salt lake city area integrated projects," Argonne National Lab.(ANL),Argonne, IL, Tech. Rep., 1995.

[23] B. Stoll, J. Andrade, S. Cohen, G. Brinkman, and C. Brancucci MartinezAnido, "Hydropower modeling challenges," National Renewable Energy Lab.(NREL), Golden, CO (United States), Tech. Rep., 2017.

[24] M. Solomon, B. Tew, C. Gerhman, and C. Lehner, "Analysis of reservoirbased hydroelectric versus run-of-river hydroelectric energy production," LRES Capstone, Montana State University., Tech. Rep., 2015.

[25] J. Hanania, K. Stenhouse, E. Cey, L. Goodfellow, B. Afework, and J. Donev. (2018) Energy education-run-of-the-river hydroelectricity. [Online]. Available: https://energyeducation.ca/encyclopedia/Run-ofthe-river hydroelectricity

[26] G. Dielen, "Renewable energy technologies-cost analysis series: Hydropower," International Renewable Energy Agency, 2012.

[27] Y. Luo, M. Mohanpurkar, R. Hovsapian, V. Gevorgian, E. Muljadi, and V. Koritarov, "Enhancing the flexibility of generation of run-of-the-river hydro power plants," Idaho National Lab.(INL), Idaho Falls, ID, Tech. Rep., 2018.

[28] S. Niu and M. Insley, "On the economics of ramping rate restrictions at hydro power plants: Balancing profitability and environmental costs," Energy Economics, vol. 39, pp. 39-52, 2013.

[29] P. March, "Flexible operation of hydropower plants." Electric Power Research Institute.(EPRI), Palo Alto, CA, Tech. Rep., 2017.

[30] V. Koritarov, T. D. Veselka, J. Gasper, B. M. Bethke, A. Botterud, J. Wang, M. Mahalik, Z. Zhou, C. Milostan, J. Feltes, Y. Kazachkov, T. Guo, G. Liu, B. Trouille, P. Donalek, K. King, E. Ela, B. Kirby, I. Krad, and V. Gevorgian, "Modeling and analysis of value of advanced pumped storage hydropower in the united states," Argonne National Lab.(ANL),Argonne, IL, Tech. Rep., 2014.

[31] M. Manwaring, D. Mursch, and K. Tilford, "Challenges and opportunities for new pumped storage development," A White Paper Developed by NHA's Pumped Storage Development Council. NHA-Pumped Storage Development Council, USA, 2012.

[32] M. Valavi and A. Nysveen, "Variable-speed operation of hydropower plants: Past, present, and future," in 2016 XXII International Conference on Electrical Machines (ICEM). IEEE, 2016, pp. 640-646.

[33] C. Nicolet, A. Beguin, B. Kawkabani, Y. Pannatier, A. Schwery, and F. Avellan, "Variable speed and ternary units to mitigate wind and solar intermittent production," Hydro Vision, 2014.

[34] Z. Dong, J. Tan, E. Muljadi, R. Nelms, and M. Jacobson, "Impacts of ternary-pumped storage hydropower on u.s. western interconenction with extremely high renewable penetrations," in 2019 IEEE Power Energy Society General Meeting (PESGM), 2019, pp. 1-5.

[35] F. Qiu and P. Li, "An integrated approach for power system restoration planning," Proceedings of the IEEE, vol. 105, no. 7, pp. 1234-1252, 2017.

[36] M. M. Adibi and L. H. Fink, "Overcoming restoration challenges associated with major power system disturbances - restoration from cascading failures," IEEE Power and Energy Magazine, vol. 4, no. 5, pp. 68-77, 2006.

[37] B. Vaagensmith, T. McJunkin, K. Vedros, J. Reeves, J. Wayment, L. Boire, C. Rieger, and J. Case, "An integrated approach to improving power grid reliability: Merging of probabilistic risk assessment with resilience metrics," in 2018 Resilience Week (RWS), Aug 2018, pp. 139146. 